\section{Estudo \\ cobebate}

em CAStão

Plamejamento
Revista Estudo \& Debate, Lajeado, v. 28, n. 4, 2021. ISSN 1983-036X

DOI: http://dx.doi.org/10.22410/issn.1983-036X.v28i4a2021.2925

\title{
GEOPOLÍTICA DOS RECURSOS NATURAIS ESTRATÉGICOS E O PAPEL DO ESTADO BRASILEIRO
}

\author{
Tathiane Marques Dorneles ${ }^{1}$, Tailiny Ventura ${ }^{2}$, Luz Marina Lopes Almeida ${ }^{3}$
}

\begin{abstract}
Resumo: $\mathrm{O}$ controle e a gestão de recursos escassos são expressóes contemporâneas da geopolítica global, na qual, a apropriaçáo e a defesa de certas riquezas constituem um alicerce para a construção de um projeto nacional de desenvolvimento. Nesta perspectiva, este trabalho busca discutir a relação entre a geopolítica dos recursos estratégicos e o papel do Estado brasileiro na articulação e defesa dos interesses nacionais. A exploração destes recursos permitiu que o país obtivesse avanços em termos de geração de tecnologia e garantiu sua inserção competitiva no mercado mundial. Entretanto, estes mesmos recursos podem ser utilizados como ferramentas coercitivas e de pressão por Estados hegemônicos e suas corporaçôes, criando desafios à posiçáo do Brasil quanto ao controle e uso de suas riquezas naturais. Para discutir essas questóes traçamos um panorama comparativo entre o pensamento estratégico brasileiro formal e o papel efetivo do governo na defesa dos interesses nacionais.
\end{abstract}

Palavras-chave: Geopolítica; Recursos Naturais; Interesses Estratégicos, Desenvolvimento.

\section{GEOPOLITICS OF STRATEGIC NATURAL RESOURCES AND THE ROLE OF THE BRAZILIAN STATE}

\begin{abstract}
The main objective of this article is to analyses the relationship among the geopolitics of strategic resources and the role of the Brazilian state in the articulated and in defense of national interests. To do this, in the first section we presented the classical theoretical foundations and the contemporary discussion of two new paradigms in geopolitics literature. After that, the second section shows the importance of the State's role in fostering strategic sectors. The third section analyzes the importance of the geopolitics of strategic natural resources in Brazil and draws a comparative panorama between the formal Brazilian strategic thinking and the effective Government's role in defense of national interests.
\end{abstract}

Keywords: Geopolitics; Natural resources; Strategic interests, Development.

1 Economista, Mestra em Agronegócios, doutoranda em Economia pelo CEDEPLAR / UFMG

2 Economista, Mestra em Desenvolvimento Econômico, doutoranda em Economia pelo CEDEPLAR / UFMG

3 Economista, Mestra em Economia, doutoranda em Economia pelo CEDEPLAR / UFMG 


\section{Introdução}

A era da globalização contribui para a busca progressiva de meios para a manutenção do crescimento do produto das economias, o que conduz a temática da exploração dos recursos naturais para uma perspectiva geopolítica de segurança e interesse nacional. A crescente demanda mundial por bens que podem se tornar escassos têm colocado as regióes com abundância desses recursos no centro das atençóes internacionais. No Brasil, as potencialidades energéticas e minerais, a biodiversidade e a própria extensão geográfica têm suscitado desafios relacionados à criação de normas e à condução de políticas públicas para o acesso e controle dos recursos estratégicos.

Neste contexto, a geopolítica, enquanto ciência que estuda e analisa a influência de fatores geográficos, históricos, políticos e sociais na conformação do poder dos Estados, conforma um importante arcabouço teórico que nos permite compreender a relação entre crescimento econômico, soberania nacional e a atuação estratégica dos países. Ademais, a formulação de políticas para o controle e uso de recursos escassos são expressóes contemporâneas da geopolítica global, na qual a apropriação e a defesa de certas riquezas constituem o alicerce para a construçáo de um projeto nacional de desenvolvimento.

A demanda internacional por recursos naturais em seus mais diversos setores, em especial o de commodities minerais como petróleo, gás e ferro; agrícolas como soja e milho, além da água como insumo indispensável para realização de qualquer atividade econômica, cresce à medida que as naçóes expandem suas economias. À frente deste processo encontramse países e regióes que buscam fontes alternativas de suprimento de recursos visando a manutenção de poder, como os Estados Unidos e a União Europeia, bem como, novas potencias econômicas como a China, cuja enorme pressão por recursos estratégicos têm definindo um novo panorama na conjuntura internacional.

Para Amin (2015), a crescente demanda externa por recursos naturais estratégicos tem definido uma configuração geopolítica singular, através da qual as regióes ricas nesses recursos tornam-se centrais para os interesses econômicos de países hegemônicos que fazem uso intensivo de matérias-primas, e que portanto, são capazes de determinar a regionalização geopolítica dos novos padrôes de exploração e comercialização de recursos produtivos. Nesse contexto estão inseridas as discussóes sobre apropriação e controle dos recursos naturais, pois, como bem apontado por Becker (2012, p.117), "o modo pelo qual o espaço é apropriado e gerido e o conhecimento desse processo constituem, ao mesmo tempo, expressão e condição das relações de poder".

A posse e a gestão econômica e científica dos recursos naturais abrem espaço para consolidação de uma estratégia nacional de crescimento e soberania. A apropriação das inovaçóes tecnológicas geradas a partir da exploração de recursos naturais contribui para a garantia dos interesses nacionais de duas formas principais: primeiro, porque o desenvolvimento tecnológico tende a equilibrar capacidades entre países. Nesse sentido, configura-se como uma estratégia política e econômica de ratificação do Estado soberano num contexto regido por um processo de globalização pautado na via dos mercados. Segundo, trata-se de uma importante ferramenta para a construção de um projeto de desenvolvimento que inclua, também, o aproveitamento das vantagens comparativas sobre os ativos naturais. 
Este trabalho busca discutir a relação entre a geopolítica dos recursos estratégicos e o papel do Estado brasileiro na manutenção e defesa dos interesses nacionais. Argumentamos que, nos países em desenvolvimento como o Brasil, a açáo do Estado constitui peça fundamental para o progresso de setores específicos como o incremento de tecnologias e inovação que contribuem para o crescimento econômico e o bem-estar social da população e, são considerados estratégicos para a construção da autonomia e afirmação dos interesses nacionais no âmbito da geopolítica internacional.

Para o aprofundar estas discussōes, o trabalho está organizado da seguinte forma: a primeira seção resgata um fundamento teórico clássico da geografia política para articular a discussão contemporânea dos novos paradigmas da geopolítica. A segunda seção discute a importância da atuação do Estado no fomento a setores estratégicos da economia e suas implicaçóes para a autonomia tecnológica e o desenvolvimento econômico. A terceira seção analisa a importância da geopolítica dos recursos naturais estratégicos no Brasil e traça um panorama comparativo entre o os documentos que norteiam o pensamento estratégico brasileiro e a atuação do Governo na defesa dos interesses nacionais. Estes documentos são: o Livro Branco de Defesa Nacional (2012), a Estratégia Nacional de Defesa e a Política Nacional de Defesa (2012) e o Livro Verde de Defesa (2017). Por fim, são apresentadas as conclusóes.

\section{Novos paradigmas da geopolítica: o papel dos recursos naturais no século XXI}

O debate sobre a relevância dos recursos naturais evidencia o caráter singular do processo de apropriaçáo e gestáo de bens escassos diante dos interesses estratégicos dos Estados hegemônicos e dos desafios para o crescimento econômico dos páses. Esses recursos são insumos importantes para a manutenção do padrão de acumulação capitalista das naçôes e, estabelecem influências geográficas que impactam as decisóes políticas e a hierarquia econômica entre os Estados. Estas características reforçam a necessidade de repensar o contexto das políticas nacionais de defesa, dado a especificidade de determinadas riquezas para a construção de um projeto nacional do desenvolvimento.

A relação entre recursos naturais e desenvolvimento econômico pode ser analisada, em uma perspectiva geopolítica, a partir do conceito de "espaço vital" criado por Friedrich Ratzel (1844-1904). As relaçóes entre o Estado, sociedade e o solo estáo presentes no arcabouço analítico desenvolvido pelo geógrafo alemáo, que avançou na teorização sobre o Estado a partir de uma visão organicista que condicionava a sobrevivência de uma nação à necessidade de expansão do território e apropriação de recursos naturais.

Por espaço vital compreende-se a fração de território necessária para o desenvolvimento social e econômico de um povo. Neste contexto, é papel do Estado garantir que cada naçáo possa extrair de seus respectivos territórios as condiçôes concretas para seu desenvolvimento (MORAES, 1990). Depreende-se desse conceito dois argumentos sobre a relação entre população, território e recursos: a exploraçáo dos recursos naturais é parte intrínseca do processo de transformação econômica de uma regiáo e, a concepção de que toda nação que almeja o desenvolvimento necessita de um "espaço vital". 
Neste sentido, além de espaço enquanto território, o Estado necessita de recursos naturais em abundância para crescer e para sustentar sua existência. Logo, a busca por novos espaços e a capacidade de transformaçáo de seus recursos em riqueza efetiva, seriam determinantes para o desenvolvimento de uma nação ou de um povo (COSTA, 2013).

A clássica discussão em torno da teoria do espaço vital proposta por Ratzel apresenta argumentos geopolíticos que podem ser repensados à luz das novas relaçóes de poder entre os Estados. Partindo da concepçáo de que os países ricos em recursos naturais teriam a possibilidade de alcançar vantagem estratégica na conformação de poder, observamos o estabelecimento de modelos autárquicos que permitem a sustentaçáo de projetos de domínio econômico e político. Desta forma, a disponibilidade de recursos naturais abre espaço para uma dinâmica em que o território nacional é colocado como um elemento central de consolidaçáo de poder frente ao cenário internacional.

A reconfiguração territorial e as novas relações de poder estabelecidas no Pós-Guerra Fria conduziram o campo da geopolítica a discussōes contemporâneas, que envolvem temas voltados à dinâmica da nova ordem mundial, considerando aspectos políticos, econômicos, sociais e ambientais. Nesta perspectiva, foram incorporados debates sobre o controle de espaços geográficos estratégicos e os conceitos de segurança alimentar e energética. Autores como, Homer-Dixon (1994); Klare (2001) e Le Billon (2004) conduzem a temática da exploração dos recursos naturais para uma perspectiva geopolítica de segurança e interesse nacional, em que, a possibilidade de futuros conflitos entre as naçóes não está relacionada a questóes políticas ou ideológicas, mas sim, com a disputa pela posse de recursos naturais estratégicos.

Homer-Dixon (1994) argumenta sobre uma relação causal entre a escassez de recursos renováveis e conflitos violentos em muitos países em desenvolvimento. $\mathrm{O}$ autor descreve as três principais motivações para a escassez de recursos renováveis: a mudança ambiental, o crescimento populacional e a distribuiçáo social desigual de recursos. Tais fenômenos, entretanto, estão relacionados à açáo de grupos de maior poder econômico que imperam na organizaçấo dos direitos de propriedade. Estes conduzem a distribuiçáo de recursos e influenciam no resultado de projetos de desenvolvimento de larga escala ou novas tecnologias e alteram os valores relativos destes recursos.

Assim, a possível escassez de recursos renováveis combinada com o crescimento da população e aumento da produção econômica global reforça a tendência destes grupos de modificar a distribuição de recursos em prol de seus interesses, o que pode ocasionar em problemas ambientais e aumento de escassez nos grupos mais pobres. Este processo de interação é denominado por Homer-Dixon (1994), como "captura de recursos". Como efeito, o aprofundamento do acesso desigual aos recursos naturais tende a gerar movimentos intensos de migraçóes a regióes de risco ambiental, e conflitos civis e internacionais, especialmente em países com maior nível de desigualdade.

Le Billon (2004) ratifica a possibilidade do aumento de conflitos armados relacionados às disputas por recursos naturais estratégicos. Segundo o autor, o potencial econômico de recursos naturais em países em desenvolvimento e, a relação entre exploração de recursos e a estabilidade política permanecerá central nos próximos anos, principalmente quando observados cenários semelhantes nestes países, que perpassam por movimentos de colapso 
do crescimento, de corrupção e de processos de deslegitimação da autoridade do Estado. A competição se intensifica quando os recursos correspondem a água, o petróleo e o gás natural, por exemplo.

A disputa por recursos e poder é tratada por Klare (2001) no livro Resource Wars: the new landscape of global conflict. O principal foco é a orientação dos Estados Unidos sobre a posse e o controle de suprimentos estratégicos que são, ou virão a ser, razão para conflitos entre diferentes países no século XXI. Isto porque, uma parte considerável das reservas de recursos essenciais como petróleo e água doce, por exemplo, estáo concentradas no território de poucos países, o que imprime um caráter intervencionista na atuação dos Estados hegemônicos. Nesse sentido, os Estados deveriam adotar um comportamento estratégico no que consiste às políticas de segurança e controle de recursos naturais.

A opugnação de países hegemônicos que buscam aumentar seus "espaços vitais", ou, em outras palavras, que buscam o domínio de regiōes ricas em recursos estratégicos, torna cada vez mais urgente e relevante a discussão sobre a atuação dos países em desenvolvimento em relação à segurança e o domínio de suas riquezas. Este cenário imprime novos desafios geopolíticos relacionados às garantias de defesa nacional e de soberania, além da gestão ótima das riquezas naturais do território. Os desafios se estabelecem, portanto, no campo do delineamento dos interesses e da conduçáo das políticas de defesa, bem como, do estabelecimento prioritário de investimentos em pesquisa e inovação para a transformação dos recursos naturais disponíveis em riqueza efetiva. Nestes moldes, o Estado exerce importante papel no que concerne à governança de sua base natural estratégica.

\section{A intervençáo estatal em setores econômicos estratégicos}

$\mathrm{O}$ aumento da demanda internacional por commodities estratégicas (sejam minerais, energéticas, agrícolas ou ambientais) revela um novo panorama mundial, em que a escassez de recursos e a busca por fontes alternativas produzem açóes que se manifestam na forma de extensão de poder. A partir desse contexto, países como o Brasil, ricos em recursos naturais, se confrontam com um ambiente internacional em que o controle desses insumos é alvo de interesse de grandes potências econômicas, passando a determinar a geopolítica dos padrōes de exploração e comercialização vigentes (AMIM, 2015).

No mercado internacional, o aumento da demanda por commodities tem incentivado o desenvolvimento de novas tecnologias que permitem intensificar a exploraçáo desses recursos, uma vez que a consolidaçáo do processo tecnológico pode aumentar substancialmente os resultados dos investimentos nesses setores. Bielschowsky (2013) destaca que a inovação tecnológica permite transformar em núcleos estruturantes da economia nacional atividades que ainda não estáo sendo executadas e aquelas incipientes, reforçando o encadeamento das produçóes com alto padrão de sofisticação e valor agregado.

Além do interesse nas riquezas naturais, a atenção internacional se externa nas regiōes com abundância desses recursos. No caso brasileiro, podemos destacar a região Amazônica e os Cerrados, além da camada do Pré-sal presente em território marítimo. Associado a esses interesses se encontra a necessidade de criação de novas tecnologias, uma vez que estas possibilitam a exploração dos recursos de forma mais intensa, ampliando a oferta 
de commodities e dos recursos estratégicos brasileiros. Nesse sentido, é necessário um alto esforço em termos de pesquisa e desenvolvimento voltado para tecnologia nesses setores.

Nessa perspectiva, Becker (2005) afirma que a natureza é vista como um recurso escasso e, da mesma forma, como uma reserva de valor, em função da possibilidade de uso da biodiversidade associada ao avanço tecnológico, permitindo assim, a intensificaçáo da exploração. O Brasil já passou por três grandes transformaçóes tecnológicas associadas à biodiversidade: a correção dos solos do cerrado, a transformação de cana de açúcar em combustível na Mata Atlântica e o desenvolvimento da exploração do petróleo em águas profundas. Ademais, ressalta-se a importância de uso de novas tecnologias na regiáo Amazônica, que permitem o estabelecimento das chamadas cadeias tecno-produtivas. Esse desenvolvimento de tecnologia associada ao uso dos recursos naturais no Brasil está ligado, fundamentalmente, a esforços estatais.

Em economias em processo de desenvolvimento, como o Brasil, é fundamental uma atuação por parte do Estado no que se refere aos investimentos em inovaçóes tecnológicas, dada a baixa acumulação dessas economias. De forma específica, esforços tecnológicos nessa direção são de longo prazo e demandam alto nível de investimento, associados, por exemplo, ao custo elevado de indústrias extrativas (MEDEIROS, 2013). Nesse sentido, a necessidade de atuação estatal nesse processo se manifesta de duas formas: primeiro, pela questão geopolítica, que confere a soberania de Estados detentores de recursos estratégicos, segundo, porque o setor privado, guiado pelos mecanismos do mercado náo se dispóe a financiar investimentos de tal magnitude.

A partir desse raciocínio, cabe destacar o interesse externo de desenvolvimento de empresas de alta tecnologia no Brasil, voltadas para esses setores, uma vez que facilitam e intensificam a exploraçáo dos recursos nacionais. $\mathrm{O}$ uso de tecnologias associado à abundância desses recursos se torna interessante porque permite a redução dos custos de produção e extração. É necessário ressaltar a importância da proteção desses recursos, haja vista o interesse internacional nas áreas abundantes em recursos estratégicos. Assim, o Estado se vê desafiado a adotar uma postura política austera no que se refere ao uso desse patrimônio natural em prol do crescimento do país e, ao mesmo tempo, no que permeia o uso das tecnologias desenvolvidas nacionalmente por empresas externas.

Nesse sentido, cabe notar que a visão novo desenvolvimentista, relacionada a uma estratégia de desenvolvimento associada ao uso dos recursos naturais, destaca o papel ativo e estratégico do Estado (BRESSER-PEREIRA, 2006). Faz parte dessa agenda a transformação da estrutura produtiva em prol do crescimento econômico e a melhor distribuição da renda com protagonismo das estatais e das semi-estatais no processo de especialização da estrutura produtiva com inserção externa dominante (BRESSER-PEREIRA, 2006; MILANEZ; SANTOS, 2013).

De acordo com essa abordagem o Estado é um dos principais agentes de estímulo à extração de recursos naturais, que são destinados ao mercado internacional, dessa forma, deve ser o detentor da exploração dos recursos. Portanto, cabe também ao Estado função de desenvolver as tecnologias necessárias através dos investimentos públicos. Nesse sentido, a postura do Estado deve estar direcionada a resguardar a soberania de seus recursos e, do mesmo modo, empreender no desenvolvimento de tecnologias para explorá-los. 
De forma contrária, a visão neoliberal considera que a alocação de forma eficiente dos recursos se dá através dos mecanismos de mercado, logo, a intervenção do Estado deve ser mínima. Seu papel é, portanto, coadjuvante, devendo garantir apenas boas condiçóes para a atuação das empresas (MILANEZ; SANTOS, 2013). De acordo com essa perspectiva, o Estado não deve fazer frente aos investimentos necessários ao desenvolvimento da produção e da exploração desses recursos. Assim, não cabe a ideia de um Estado nacional que irá proteger esse patrimônio e ter os direitos de propriedade de forma dominante.

A abordagem neoliberal se firmou em todo o mundo fundamentalmente nos anos 1990 ao colocar as disposiçóes do Estado mínimo e, seguindo essa linha, com a adoção de privatizaçóes. Portanto, as práticas privatizantes fazem parte dessa agenda, e considerando as empresas extrativas de recursos naturais, não há uma cautela quanto aos interesses nacionais. Campello (2018) ressalta que essa visão surge nos momentos de crises institucionais e econômicas, como uma solução aos problemas macroeconômicos dos países.

Sendo assim, a agenda neoliberal atua em prol de um equilíbrio em termos econômicos, contudo não prioriza os interesses nacionais, em termos de inserção internacional. Nesse sentido, Bielschowsky (2013) ressalta que as valorizaçóes associadas ao uso desses recursos devem ser empregadas para gerar receitas que serão aplicadas em políticas em benefício da sociedade, em absorção de forma indireta através dos tributos e não por royalties, pois esta última não é um instrumento satisfatório. Uma vez que o rendimento oriundo da exploração do recurso em si não cabe ao Estado.

A partir de uma perspectiva geopolítica, podemos considerar que o avanço tecnológico, além de uma forma de manifestação de poder, é condição importante para consolidar a soberania dos países. Entretanto, o desenvolvimento de novas tecnologias é inerente ao domínio dos recursos naturais. A trajetória de desenvolvimento das capacidades técnicas brasileiras é um bom exemplo de como o controle e a gestão dos recursos estratégicos estão intrinsecamente relacionados ao desenvolvimento e ao aprimoramento de novas tecnologias. A atuação do Estado nesse contexto, não apenas estabelece condições para o desenvolvimento econômico e social do país, como também manifesta a liderança do país nos setores estratégicos.

\section{Geopolítica dos recursos naturais e a atuaçáo do estado brasileiro}

Em uma análise convencional podemos definir os recursos naturais como fatores produtivos que vêm da natureza. Estes recursos tornam-se estratégicos por serem escassos, essenciais ou potencialmente importantes para o desenvolvimento de atividades econômicas e, portanto, são substanciais para a construção da autonomia e afirmação dos interesses nacionais no âmbito da geopolítica internacional. Neste sentido, entendemos que a dotação de recursos naturais impóe desafios políticos e econômicos no âmbito do sistema internacional e que o Brasil, enquanto nação detentora de uma grande diversidade desses ativos possui um papel de relevância no cenário global.

Nesta seção buscamos traçar um panorama comparativo entre as diretrizes presentes nos documentos que norteiam o pensamento estratégico brasileiro, publicados pelo Ministério da Defesa (MD), e a condução da política de governo (na esfera legislativa 
e executiva) na defesa dos interesses nacionais relacionados à apropriação e ao controle de recursos estratégicos como petróleo, minérios, biodiversidade, água doce e terras agricultáveis, para o desenvolvimento econômico e a soberania do Estado brasileiro. Estas estratégias constam no Livro Branco de Defesa Nacional de 2012; na Estratégia Nacional de Defesa e Política Nacional de Defesa de 2012 e, no Livro Verde de Defesa de 2017.

\subsection{Petróleo e recursos minerais}

A Política Nacional de Defesa reconhece que, "neste século, poderão ser intensificadas disputas por áreas marítimas, pelo domínio aeroespacial e por fontes de água doce, de alimentos e de energia, cada vez mais escassas", e aponta para o fato de que "tais questóes poderão levar a ingerências em assuntos internos ou a disputas por espaços não sujeitos à soberania dos Estados, configurando quadros de conflito" (MD, 2012b, p.17). A disputa por áreas marinhas, mencionada no documento, está diretamente relacionada à descoberta de petróleo e ao desenvolvimento de tecnologia para extração em águas profundas.

A geopolítica do petróleo mostra que historicamente há uma concentração de controle exercida por poucos países que, com suas grandes reservas e relaçóes políticas com os demais, mantêm o controle da oferta e, consequentemente, dos preços da commodity mundialmente. Entretanto, impulsionados pelos avanços tecnológicos e pelas grandes descobertas, outros países passaram a ganhar destaque como Canadá, Estados Unidos, Venezuela e Brasil, principalmente pela forma não convencional de extração e produção do petróleo, como areias betuminosas e, no caso do Brasil, o pré-sal.

Nesse sentido, observa-se a importância e a necessidade, em um mundo cada vez mais dependente dos combustíveis fósseis, do Brasil prosseguir desenvolvendo o pré-sal de modo a aprimorar e aumentar sua capacidade de produção. A descoberta desse recurso coloca o país entre os maiores detentores de reservas de petróleo no mundo, tornando-o potencialmente relevante (Costa, 2012) como produtor e exportador do combustível fóssil. Campello (2018) destaca que, como uma importante fonte de energia, o petróleo pode ser visto como um recurso de inserção estratégica do país, exteriorizando uma fonte para o desenvolvimento do Brasil. Dessa forma, ressalta-se o papel do Estado brasileiro no controle e regulação da exploração nacional para preservação deste importante recurso energético.

\footnotetext{
Sob o comando do Estado brasileiro, o pré-sal poderia ser desenhado como um alicerce para a construção de um projeto nacional que passasse a relacionar a inserçáo internacional do país no rol das grandes potências e que, de maneira indissociável, poderia garantir substanciais recursos empregados pelos diferentes níveis de governo no tripé: desenvolvimento social, investimentos em pesquisa energética, planejamento e recuperaçáo ambiental (CAMPELLO, 2018, p.28).
}

Como há uma tendência de crescimento do consumo mundial, o petróleo se torna cada vez mais um produto de desejo entre os países, possuindo um importante papel econômico e geopolítico na relação entre as Nações. Coloca o país, portanto, em posição de destaque no cenário internacional. Oliveira et al. (2016) ressaltam que o aumento da demanda mundial por energia leva também a maior competição entre as grandes potências pelo controle dos recursos energéticos. Nesta perspectiva, a disputa estratégica e geopolítica 
entre produtores e consumidores em torno do uso e controle do recurso, reforça a importância de um posicionamento do Estado brasileiro com relação aos recursos petrolíferos.

O Livro Branco de Defesa Nacional reconhece que confere ao Estado brasileiro o direito de exploração e os direitos territoriais a regiáo do Atlântico Sul, considerada como a "Amazônia Azul", pois representa a regiáo que possui as maiores reservas de petróleo em águas profundas e ultraprofundas (MD, 2012a). Logo, há maior necessidade de aumentar medidas de proteção, controle e monitoramento desta área. Campello (2018) ressalta que existe o ônus associado à riqueza do pré-sal em função dos interesses internacionais na área, dessa forma cabe ao Estado proteger os interesses internos. Da mesma forma, o autor estabelece as diretrizes do novo marco regulatório do pré-sal (13.365/2016) e os efeitos para o Brasil em termos de uma política nacionalista quanto a exploração do pré-sal.

No que permeia à postura do Estado brasileiro com relação ao petróleo, é necessário destacar duas questóes: primeiro, a descoberta do pré-sal fez com que houvesse um grande esforço tecnológico por parte da Petrobrás para viabilizar a extração, o que ao longo do tempo provocou queda do custo de exploraçáo. $\mathrm{O}$ Brasil se coloca no cenário mundial como uma das únicas naçōes a dominar a tecnologia de exploração petrolífera em águas profundas e ultraprofundas (CAMPELLO, 2018), o que confere ao país posição de destaque frente aos demais países no ambiente internacional.

Considerando os direitos de exploraçáo do recurso, o novo marco regulatório dispóe de forma facultativa o direito da estatal de preferência para atuar como operadora, além da não obrigatoriedade de possuir participação mínima de $30 \%$ na exploração. $\mathrm{O}$ produto dessa mudança é a abertura de maior espaço para que as empresas estrangeiras produtoras de petróleo, que enxergam no pré sal brasileiro grande potencial para redução de seus custos e aumento dos lucros (OLIVEIRA et al. 2016), após o esforço tecnológico estar finalizado. Em síntese, as mudanças que retiram a Petrobrás como a principal operadora permitem a exploração do pré-sal por outras empresas, com o uso de um esforço exclusivamente nacional de desenvolvimento de tecnologia para tal. Enquanto a tendência da geopolítica global seria de aumento do nacionalismo acerca dos recursos estratégicos, o posicionamento do governo se revela em um caminho contrário, reduzindo o papel da estatal.

Isto posto, a atual estratégia do governo brasileiro quanto à exploração de petróleo parece seguir uma linha mais liberal, privilegiado os interesses do capital privado, em detrimento do nacional com a introdução de mudanças voltadas para o mercado. A atuaçáo das empresas estatais deve ser voltada para um projeto de soberania nacional dirigida para o setor externo. Nesse sentido, Campello (2018, p. 26) afirma que "tirar a primazia da Petrobras sobre o pré-sal, inclusive com a cessão de tecnologias nacionais num setor extremamente competitivo e protecionista, pode apresentar sérios retrocessos para as pretensões geopolíticas do país". Portanto, a condução política em período mais recente aponta para uma conduta que facilita o acesso às riquezas do país por parte do capital externo. $\mathrm{O}$ autor supracitado ainda destaca que a negligência quanto ao uso deste recurso e a perda da soberania do Estado sobre o controle das reservas aumentam a área de atuação para outros países.

A disputa por recursos naturais, de forma geral, se torna cada vez mais intensa, e de modo semelhante, a geopolítica dos recursos minerais dos países em desenvolvimento integra 
a pauta de discussões estratégicas internacionais (RODRIGUEZ, 2015; MME, 2011). Os recursos minerais não combustíveis configuram um insumo estratégico fundamental para o desenvolvimento de qualquer país, uma vez que são necessários durante todas as etapas do processo de industrialização. Esse setor é a base para diversas cadeias produtivas. Além disso, alguns minerais são considerados como chave para o desenvolvimento de tecnologias de ponta, como a espacial e a nanotecnologia (BRUCKMAN, 2011; RODRIGUES, 2015). Logo, o Brasil se coloca em posição importante frente à crescente demanda mundial por bens desse setor.

A mineração é um importante setor estratégico para o crescimento econômico brasileiro. A intensidade do consumo, assim como da produção, vem aumentando desde os anos 1980 . Ao longo dos anos 2000 o produto do setor mineral cresceu de forma significativa e atualmente corresponde a aproximadamente $4 \%$ do PIB e $20 \%$ das exportaçóes brasileiras. O país ocupa posição dominante em termos de reservas minerais, com uma gama de diversificada de minerais, metálicos e não metálicos.

A participação brasileira nas reservas e na produção mundial de bens minerais constitui um importante sinalizador para a busca de novos meios a serem desenvolvidos, como a atratividade e competitividade dos bens minerais, abrindo espaço para a inserção do país no sistema internacional. O Brasil vem, nos últimos, anos atraindo investimentos no setor. Entre os fatores que estimulam os investimentos em mineração estão o potencial geológico, o acesso a mercados de exportação, infraestrutura de transporte e energia e capacitação tecnológica (MME, 2011).

No entanto, cabe ressaltar que o potencial geológico e a atração desses investimentos devem ser observados com cautela. A disputa global por esse tipo de recurso estratégico tende a direcionar os grandes consumidores para as regióes com as maiores reservas. Rodrigues (2015) considera que a estratégia de grandes potências, como China e Estados Unidos, se fundamenta a partir de açôes que se articulam para derrubar as possíveis barreiras que possam impedir o acesso a extração desses bens. Bruckman (2011), destaca o discurso estadunidense, que considera como uma estratégia de soberania nacional "o domínio dos recursos naturais a nível global”. Este panorama indica que o Brasil possui grandes desafios para manter a soberania de seus recursos, o que inclui uma forte atuação governamental.

Essa abordagem é corroborada pelo Plano Nacional de Mineração 2030 (MME, 2011), que estabelece as principais diretrizes para que o setor seja uma das bases para o desenvolvimento do país. Entre os principais objetivos do plano está a governança pública, cuja atribuição é atuar em prol do novo marco regulatório da mineração e estabelecer novas regras para a compensação financeira pela extração dos recursos. A partir disso, foi criada a Agência Nacional de Mineração no ano de 2017, o estabelecimento de obrigatoriedade por parte das mineradoras de reparar os danos, além de proibição de práticas que degradem o meio ambiente.

No entanto, por mais que as medidas representem um avanço em alguns aspectos como a destinação de $15 \%$ dos royalties para os municípios não produtores, mas que sofrem externalidades negativas - o foco central são os investimentos por parte da iniciativa privada, revelando a redução de soberania do Estado brasileiro no que tange a administração desses recursos de forma direta. Como destacado em seção anterior, é do interesse da comunidade 
internacional implementar indústrias extrativas no Brasil, as quais incluem também a exploração dos recursos minerais.

Outra crítica relacionada à atuação do Estado brasileiro quanto à gestão dos recursos minerais, é que o país não explora o processo de transformaçáo dos minerais, o que aumentaria o valor agregado dos produtos exportados. Isto confere uma baixa participação desses bens no PIB, em comparação com o seu potencial e a profusão desses recursos no território. Desta forma, é imprescindível que sejam destinados recursos para o desenvolvimento tecnológico, garantindo maior produção, competitividade e qualidade das mineradoras brasileiras. Isso vem sendo feito, porém com baixa participação estatal.

Em síntese, salienta-se a necessidade de um projeto de nação que considere a importância dos recursos minerais e petrolíferos para o desenvolvimento econômico, porém de forma a consolidar a soberania do país. Esses recursos fazem parte da cadeia global de produção e, portanto, desempenham um papel fundamental na consolidação de interesses tanto econômicos quanto geopolíticos. Dessa forma, são capazes de gerar conflitos entre nações e da mesma forma, criar uma relação de subordinação se não forem criadas políticas em prol da soberania do Estado brasileiro.

\subsection{Biodiversidade, potencial hídrico e terras agricultáveis}

As tensóes relativas à distribuição, acesso e uso dos recursos naturais estão relacionadas à percepção de escassez de meios como florestas, água e terras agricultáveis. Encontram-se, portanto, associadas à produção de alimentos e energia, à saúde humana e dos ecossistemas e à estabilidade social, econômica e política dos países. A quantidade e a diversidade das reservas naturais presentes no Brasil exercem papel fundamental frente à crescente demanda mundial por recursos naturais e conduz o país a uma posição estratégica frente aos interesses hegemônicos de potências econômicas mundiais. Esta percepção está presente no Livro Branco da Defesa Nacional quando reconhece que "novos temas - ou novas formas de abordar temas tradicionais - passaram a influir no ambiente internacional deste século, em especial, no que tange à proteção da biodiversidade, a biopirataria e as tensóes decorrentes da crescente escassez de recursos" (MD, 2012a, p.28).

O Brasilé o terceiro maior produtor e exportador agrícola do mundo. Posição alcançada após a ocupação produtiva do bioma Cerrado por médios e grandes empreendimentos agropecuários, que permitiram a incorporação de extensas áreas para o desenvolvimento de atividades rurais. O país também concentra cerca de $12,5 \%$ da água doce do planeta e parte dessa disponibilidade encontra-se em reservatórios subterrâneos como os aquíferos Alter do Chão e Guarani. Além disso, possui a maior bacia hidrográfica do mundo em uma área que conserva o maior depósito de biodiversidade do planeta, a Amazônia. A imensa variedade de recursos e a importância de sua proteção é reconhecida no Livro Verde de Defesa ao apontar que "o Brasil é marcado por riquezas naturais diversificadas e cabe à Defesa não apenas proteger esse patrimônio, mas ajudar na sua preservação (MD, 2017, p.6).

$\mathrm{O}$ aumento da atividade produtiva mundial e o próprio crescimento populacional aumentam a demanda por recursos naturais e podem intensificar as disputas por fontes de água doce, de alimentos e de energia. Este é um tema recorrente nos documentos oficiais 
e, a partir desta perspectiva, fica a cargo do Ministério da Defesa e, também, do Ministério do Meio Ambiente e de suas autarquias, desempenhar um papel protagonista na proteção do meio ambiente, por meio de normas e, sobretudo, de fiscalização. Portanto, é patente que exista um projeto de defesa nacional que reconheça a importância dos recursos naturais estratégicos e, sobretudo, reconheça a função do Estado em protegê-los.

Entretanto, não podemos deixar de considerar que a definição das ações voltadas para a manutenção estratégica dos recursos naturais depende da estrutura de poder político vigente e dos grupos de interesses por ele representados. De forma geral, a estratégia brasileira de defesa relacionada aos ativos naturais está focada sobretudo no uso das forças armadas para a proteção dos recursos, conforme consta nos documentos oficiais. Em termos governamentais, as açóes estabelecidas atualmente no âmbito Federal estão mais alinhadas com um discurso econômico liberal, cujas implicações já podem ser observadas no tocante à flexibilização de normas para proteção ambiental que facilitam o avanço de determinadas atividades econômicas.

Este descompasso fica claro quando consideramos a relevância geopolítica da Amazônia, determinada por seu grande estoque de recursos estratégicos como a extensa biodiversidade, a riqueza mineral e o potencial hídrico. De acordo com Becker (2005), há um processo crescente de mercantilização da natureza e num contexto global, a região passa a ser a grande fronteira do capital natural. Este movimento iniciou-se com as mudanças estruturais que ocorreram na Amazônia ao final do século XX e resultaram em uma dinâmica de valorização da região que pode ser observada pela lógica da acumulação, onde a biodiversidade e a água são tratadas como reserva de valor que podem possibilitar avanços tecnológicos futuros.

Neste contexto, Shiva (2001) chama atenção para o processo de "privatização do conhecimento da biodiversidade”. A utilização destes recursos como matéria-prima industrial e os novos sistemas de propriedade intelectual, tem reforçado discursos que englobam termos como "biodiversidade global" e "recursos genéticos globais". Entretanto, a autora defende que "a biodiversidade não é uma terra comunitária global”, mas sim, específica de seu lugar de existência e forma de exploração, tratando-se de um recurso local e comunitário. Essa oposição de ideias tem gerado conflitos em torno da noção de propriedade privada e comunitária e, entre o uso global e local da diversidade biológica.

Para Amin (2015) a potencialidade dos recursos naturais, enquanto fonte estratégica para geração de inovação tecnológica denota uma nova realidade geopolítica para a Amazônia em que a maior presença do Estado é fundamental para reafirmar a soberania da região. Neste sentido, Becker (2005) afirma que o movimento de mercantilização é irreversível, cabendo ao governo e à sociedade estabelecer as regras para a regulação desses mercados além da promoção de uma política de consolidação do desenvolvimento dessas regióes.

Esta visão é corroborada pela Estratégia Nacional de Defesa, documento que contém as diretrizes e planejamento de açóes destinadas à defesa nacional, que afirma que "a Amazônia brasileira, com seu grande potencial de riquezas minerais e de biodiversidade, é foco da atenção internacional" e, portanto, deve ser tratada como a maior "vulnerabilidade" estratégica nacional do país (MD, 2012b). 
O Brasil será vigilante na reafirmação incondicional de sua soberania sobre a Amazônia brasileira. Repudiará, pela prática de atos de desenvolvimento e de defesa, qualquer tentativa de tutela sobre as suas decisóes a respeito de preservação, de desenvolvimento e de defesa da Amazônia. Não permitirá que organizaçóes ou indivíduos sirvam de instrumentos para interesses estrangeiros - políticos ou econômicos - que queiram enfraquecer a soberania brasileira. Quem cuida da Amazônia brasileira, a serviço da humanidade e de si mesmo, é o Brasil (MD, 2012b, p. 54).

Não obstante, dados do Instituto Nacional de Pesquisas Nacionais (INPE) apontam para o avanço da área desmatada, além do crescimento sobremaneira dos incêndios florestais. Estes crimes relacionam-se com a atuação de posseiros, madeireiros e garimpeiros que exercem atividades ilegais em terras indígenas e de proteção ambiental. A ingerência do governo brasileiro sobre áreas de preservação florestal tem gerado uma grande repercussão geopolítica que passa por discursos estadistas com ameaça de sanções econômicas e até açôes práticas como os cortes sofridos ao repasse de recursos do Fundo Amazônia para a Amazônia Legal.

$\mathrm{Na}$ contramão da literatura que nos fornece base para o desenho de políticas públicas que incentivem a exploração econômica sustentável dessas áreas, no Legislativo brasileiro tramitam projetos de Lei para a expansão de atividades de grande impacto ambiental como a monocultura agrícola e a mineração. A apresentação de projetos de Lei que propóem acabar com as atuais restriçóes à compra de terras por investidores privados internacionais (PL 4.059/2012, PL 2.963/2019), são exemplos claros de medidas que buscam atender a interesses privados colocando em risco a soberania nacional. O principal intuito é flexibilizar as regulaçóes implantadas em 2010, que tornaram mais rígida a Lei no 5.709/71, que regulamenta a compra de propriedades rurais por estrangeiros, limitando a venda de terras brasileiras a estrangeiros ou empresas brasileiras controladas por estes. Mais recentemente, $o$ Projeto de Lei 2.633/20, conhecido como PL da regularização fundiária ou PL da grilagem, a depender da interpretação que se faz sobre as intenções que o sustenta, pretende repassar cerca de 65 milhóes de hectares de terras públicas em todo território nacional, especialmente na Amazônia.

Por outro lado, a legislação do país tem avançado em setores como a proteção da biodiversidade. $\mathrm{O}$ artigo 225 da Constituição Federal, parágrafo $1^{\circ}$ inciso II, determina que o Poder Público deve preservar a diversidade e a integridade do patrimônio genético do país e fiscalizar as entidades dedicadas à pesquisa e manipulação do material genético. A Lei 13.123/2015 (Lei da biodiversidade) regulamenta o inciso II e define regras para o acesso ao patrimônio genético, ao conhecimento tradicional associado e à repartiçáo dos benefícios oriundos desse acesso e, reformulou o marco legal vigente desde 2001. Ainda que seja passível de diversas críticas, em especial por parte de pesquisadores e cientistas, a Lei é um avanço em termos do tratamento geopolítico de aspectos da diversidade biológica brasileira.

Outro ponto de interesse é o potencial hídrico da regiâo amazônica. Para Amin (2015, p.31) "um dos aspectos mais importantes das relaçóes internacionais do momento compreende a crise da água e as repercussōes geopolíticas sobre a Amazônia". Considerada a maior reserva hidrográfica do planeta, a regiâo possui valor estratégico, econômico e social 
diante da iminente escassez deste recurso, a ponto de Becker (2005), considerar a água como o "ouro azul" do século XXI.

Existem duas visões distintas sobre o consumo da água doce: a primeira, baseada na lógica da mercantilização, que pretende fazer deste recurso uma commodity e, a segunda, que considera a água como direito humano universal e reafirma a soberania e gestão pública deste recurso e a restrição da ação de grandes corporaçóes. Para Costa (2003) por trás do discurso sobre uma possível crise mundial no abastecimento de água potável está o interesse na apropriação privada do recurso, abrindo espaço para sua mercantilização. Desta forma, a gestão dos recursos hídricos envolve um problema de governança relacionado às diferentes formas de apropriação, uso e conservação da água das bacias hidrográficas e dos aquíferos e sua demanda em relação às diferentes formas de consumo, doméstico, rural, industrial ou para geração de energia limpa através de hidroelétricas.

A geopolítica dos recursos hídricos também está presente nas discussóes sobre a ampliação de áreas produtivas no Cerrado brasileiro, regiâo se caracteriza pela vasta hidrografia. Para Campos Filho (2010, p.93) "em um mundo cuja perspectiva de produçáo alimentar é de intensas disputas para garantir abastecimento de populaçóes urbanas em acelerado crescimento, o cerrado torna-se alvo em potencial dos interesses econômicos". A hidrografia da região contribui para a formação das principais bacias brasileiras além de abrigar em seu subsolo, o aquífero Guarani, importante reservatório de água doce.

Estimativas da Food and Agriculture Organization (FAO) indicam que até 2050 a produção agrícola precisará crescer globalmente $70 \%$ em quase todos os países em desenvolvimento, para alimentar a crescente população, excluindo a demanda adicional por culturas como matéria prima para biocombustível. Este cenário insere o Cerrado brasileiro no centro de disputas geoeconômicas intensificando a produção de commodities agrícolas para garantir o abastecimento das superpotências e das economias em ascensão.

O Cerrado tem importância fundamental para o Brasil, tanto em termos de biodiversidade e recursos hídricos, quanto da produção agrícola desenvolvida na região. $\mathrm{O}$ bioma se estende por $23 \%$ do território brasileiro e atualmente responde por cerca de $60 \%$ da produção agrícola anual no país. O sucesso da ocupação do Cerrado para o desenvolvimento de atividades agrícolas pode ser creditado à atuação do governo no incentivo a busca de novas tecnologias e novas técnicas de manejo do solo e dos recursos naturais. A Empresa Brasileira de Pesquisa Agropecuária (Embrapa), fundada em 1972 e considerada a maior instituição pública de pesquisa do país, é responsável pelo desenvolvimento de pesquisas e tecnologias, serviços e inovaçóes aplicadas à agropecuária brasileira que, além de garantir a soberania alimentar, transformaram o país em um dos maiores produtores de alimentos do mundo.

Apesar do elevado retorno, a parcela dos recursos dedicada à pesquisa agrícola no Brasil é muito pequena, quando comparada à de diversos outros países. Nos últimos anos, a instituição tem sofrido com a crise política e com o contingenciamento de gastos do governo provocando redução orçamentária e mudanças estruturais que incluem o fechamento de unidades de pesquisa. Ademais, tramita no Congresso brasileiro, o projeto de Lei PL 5.234/2016, que prevê a criação de uma subsidiária que permitiria acordos privados com interesse no banco de patentes da estatal, que se encontra na fronteira de pesquisas de 
melhoramento genético. Trata-se de um patrimônio público de alto valor estratégico para a nação.

Becker (2005, p.85) afirma que, "florestas e terras são bens públicos e, por isso, são trunfos que estáo sob o poder do Estado, que tem autoridade para dispor deles, segundo o interesse da nação". É clara a importância dos recursos naturais estratégicos em um contexto de crescimento da população mundial, emergência de novas economias, e o aumento da necessidade de alimentos, energia e matérias primas. Estes recursos desempenham um importante papel na formação dos interesses econômicos e geopolíticos de um Estado e sua distribuição e dependência assimétrica podem desencadear conflitos entre as naçóes. Nesse sentido, tanto a biodiversidade como os recursos hídricos e as terras agricultáveis mostram sua importância econômica e constituem elementos centrais na questão de segurança estratégica brasileira.

\section{Conclusão}

A exploração econômica dos recursos naturais brasileiros como a extração de substâncias minerais, de petróleo e gás natural, a exploração do potencial hídrico e da biodiversidade do país, bem como toda a geração de inovação tecnológica que permitiu o avanço da agricultura sobre as áreas do cerrado, têm suscitado debates a respeito do uso sustentável dos recursos naturais e sobre a soberania do Estado na manutenção e exploraçáo desses recursos. O primeiro caso relaciona o desenvolvimento econômico regional com a conservação da biodiversidade. O segundo, trata da crescente competição pelo controle estratégico dos recursos naturais e das possibilidades de conflitos inerentes a essa situação.

A teoria geopolítica clássica oferece elementos de análise que permitem reconhecer a relevância dos recursos naturais estratégicos para o Estado, bem como, lançar reflexóes atuais sobre as relaçóes de disputas de poder que ensejam desafios de ordem política e estrutural para o Brasil, principalmente enquanto ator com possibilidades reais de ampliar sua soberania e poder político frente à ordem mundial, ao tomar consciência da grande concentração de reservas naturais/minerais e de biodiversidade necessárias para a nova fronteira científico tecnológica.

Contudo, a autonomia soberana das novas fontes de matérias-primas, o fomento à ciência, tecnologia e inovação, apresentam grandes desafios. São estabelecidos novos padróes que envolvem o desenvolvimento sustentável, a redução dos abismos socioeconômicos, e o estabelecimento conjunto de soberania, a fim de que uma efetiva integração geopolítica aconteça mediante clareza política das necessidades para potencializar o poder estratégico não utilizado efetivamente.

O Brasil possui abundância de recursos naturais e, ao longo dos últimos anos, experimentou um progresso técnico associado ao uso de tais recursos, colocando-o em posição de destaque no cenário internacional. $O$ avanço na tecnologia agrícola, o desenvolvimento da exploração em águas profundas são exemplos da consolidação em termos tecnológicos nesses segmentos. Porém, é necessário destacar que o país possui grandes desafios relacionados à gestão e ao uso dos recursos naturais estratégicos. 
Os documentos oficiais de defesa demonstram que existe consciência dos atores políticos quanto a relevância estratégica da grande concentração de reservas naturais no Brasil, indispensáveis para o avanço da fronteira científico/tecnológica do país. Por outro lado, na prática, existem grandes desafios relacionados à gestão e ao uso desses recursos que poderiam ser, em parte, solucionados a partir de uma postura mais desenvolvimentista do Estado e de seus representantes no legislativo e no executivo, o que permitiria combater o aprofundamento das relações de dependência e subordinação do Brasil aos países hegemônicos.

Nesse aspecto, é importante observar que no atual contexto político brasileiro o poder público náo se encontra alinhado com ideias de natureza nacionalista e/ou desenvolvimentistas. Como resultado, as decisóes de Estado refletem a desarticulação da política externa brasileira e uma posiçấo contrária a manutençáo dos recursos naturais como forma de inserção estratégica no Sistema Interestatal. Há um comprometimento maior com propostas de cunho neoliberal e com açóes voltadas à privatização de empesas estratégicas para a soberania nacional, inviabilizando, assim, a afirmação do país como ator geopolítico global.

O reconhecimento da importância dos recursos naturais para o desenvolvimento econômico do Brasil é imprescindível para o desenho de políticas públicas que garantam a defesa dos interesses nacionais em um contexto global. Entretanto, também é esperada uma postura mais ativa do Governo na defesa dos interesses nacionais, uma vez que, não é possível conceber um projeto nacional de desenvolvimento que não considere como meio fundamental a exploração racional e autônoma de seu capital natural. O aproveitamento destes recursos permitiu que o país obtivesse avanços em termos de geraçáo de tecnologia e garantiu sua inserção competitiva no mercado mundial em conformidade aos interesses internos. Ademais, manter os recursos estratégicos sob o controle do Estado brasileiro é crucial para o desenvolvimento de tecnologia própria e para o estímulo de cadeias nacionais de produção, gerando renda e emprego e desenvolvendo a nação.

\section{Referências}

AMIN, M. M. A Amazônia na geopolítica mundial dos recursos estratégicos do século XXI. Revista Crítica de Ciências Sociais, n. 107, p. 17-38, 2015.

BECKER, B. K. Geopolítica da Amazônia. Estudos avançados, v. 19, n. 53, p. 71-86, 2005.

A geografia e o resgate da geopolítica. Espaço Aberto, v. 2, n. 1, p. 117-150,

2012.

BIELSCHOWSKY, R. Estratégia de desenvolvimento e as três frentes de expansão no Brasil: um desenho conceitual. Texto para Discussão. Instituto de Pesquisa Econômica Aplicada (IPEA), 2013. 
BRASIL. Lei no 5.709, de 07 de outubro de 1971. Diário Oficial [da] República Federativa do Brasil, Brasília, 11 out. 1971. Disponível em: http://www.planalto.gov.br . Constituição (1988). Constituição da República Federativa do Brasil. Brasília, DF: Senado Federal, 1988.

. Lei no 13.123, de 20 de maio de 2015. Diário Oficial [da] República

Federativa do Brasil, Brasília, 14 mai. 2015. Disponível em: http://www.planalto.gov.br

BRESSER-PEREIRA, L. C. O novo-desenvolvimentismo e a ortodoxia convencional. Sáo Paulo em Perspectiva. São Paulo, v. 20, n. 3, 2006.

BRUCKMANN, M. Recursos naturais e a geopolítica da integração sul-americana. Governança Global e a integração da América do Sul. Brasília: Instituto de Pesquisa Econômica Aplicada (IPEA), p. 197-246, 2011.

CAMPELLO, M. de M. C. Atores, interesses e diferentes concepçóes sobre as reservas do pré-sal brasileiro: comparando os marcos regulatórios de 2010 e 2016. OIKOS, v. 17, n. 3, 2018.

CAMPOS FILHO, R. P. Um olhar geopolítico sobre a água no cerrado: apontamentos para uma preocupação estratégica. In: PELÁ, M., CASTILHO, D. (orgs.) Cerrados: perspectivas e olhares. Goiânia: Editora Vieira, p. 93-112, 2010.

COSTA, W. M. da. Valorizar a água da Amazônia: Uma estratégia de inserção nacional e internacional. In: ARAGÓN, L. E.; CLÜSENER-GODT, M. (Orgs.). Problemática do uso local e global da água da Amazônia. Belém: NAEA, p. 299-320, 2003.

. Projeção do Brasil no Atlântico Sul: geopolítica e estratégia. Revista USP, n. 95, p. 9-22, 2012.

. Geografia política e geopolítica. São Paulo: Edusp, 2a Edição, $2^{a}$ reimpressão, 349 p. 2013.

FIORI, J. L. A nova geopolítica das nações e o lugar da Rússia, China, Índia, Brasil e África do Sul. OIKOS, v. 6, n. 2, 2007.

HOMER-DIXON, T. F. Environmental Scarcities and Violent Conflict: Evidence from Cases. International Security, Toronto, vol. 19, No 1, p.5-40, summer, 1994.

KLARE, M. T. Resource Wars: the new landscape of global conflict. Nova York: Metropolitan Books. 289p. 2001.

LE BILLON, P. The geopolitical economy of resource wars. Geopolitics, v. 9, n. 1, p. 1-28, 2004. 
MEDEIROS, C. Recursos naturais, nacionalismo e estratégias de desenvolvimento.

OIKOS, v. 12, n. 2, 2013.

MILANEZ, B.; SANTOS, R. S. P. dos. Neodesenvolvimentismo e neoextrativismo: duas faces da mesma moeda. Anais do 370 Encontro Anual da ANPOCS, 2013.

MINISTÉRIO DE MINAS E ENERGIA (MME). Plano Nacional de Mineração (PNM) 2030-Geologia, Mineração e Transformação Mineral. Brasília: Secretaria de Geologia, Mineração e Transformação Mineral-SGM, 2011.

MINISTÉRIO DA DEFESA (MD). Livro Branco da Defesa Nacional (LBDN). Brasília DF. 2012a. Disponível em: https://www.gov.br/defesa/pt-r/assuntos/copy_of_estado-edefesa/estrategia-nacional-de-defesa

. Política Nacional de Defesa (PND) e Estratégia Nacional de Defesa (END). Brasília DF. 2012b. Disponível em: https://www.gov.br/defesa/pt-br/assuntos/copy_of_ estado-e-defesa/estrategia-nacional-de-defesa

. Livro Verde da Defesa: Defesa \& Meio Ambiente. Brasília DF, 2017.

Disponível em: https://www.gov.br/defesa/pt-br/arquivos/estado_e_defesa/livro_verde/ livroa_defesaa_meioa_ambiente.pdf/view

MORAES, A. C. R. Ratzel: Geografia. Editora Atica, 1990.

OLIVEIRA, L. K. et al. Análise de estruturas geopolíticas e de tendências de aumento da competição interestatal internacional: contribuições para a prospecção de cenários de ameaças à soberania brasileira sobre o Pré-Sal. Revista Brasileira de Estudos de Defesa, v. 3, n. 2, 2017.

RODRIGUES, B. S. Geopolítica dos recursos naturais estratégicos na América do Sul. Perspectivas: Revista de Ciências Sociais, v. 45, 2015.

SHIVA, V. Biopirataria: a pilhagem da natureza e do conhecimento. Vozes, 2001. 